\title{
Internet of Things Business Models in Ecosystem Context-Cases of Elevator Services
}

\section{Chia Tai Angus Lai ${ }^{1,2, *}$, Paul R Jackson ${ }^{1}$ and Wei Jiang ${ }^{2}$}

${ }^{1}$ Alliance Manchester Business School, University of Manchester, Manchester, United Kingdom

${ }^{2}$ Antai College of Economics and Management, Shanghai Jiaotong University, Shanghai, China

\begin{abstract}
Companies increasingly have to adapt new technology and design new business models to retain their competitive advantage in highly dynamic environments. The increasing pervasiveness of the Internet of things (IoT) has offered great potential in many different areas of application to lead or complement new business models. However, business models based on largely static, single firm or historical information architectures are facing challenges in today's more dynamic environment as new ways of creating value arise across industries and between firms, clients and other stakeholders. Embracing the business ecosystem concept is now becoming critical in order to realize business opportunities or business model potential. This paper focuses on the elaboration of the business ecosystem concept in the IoT business model environment, from both academic and practitioners' perspectives, to analyse how IoT business models are connected to the underlying business ecosystem. We analyse three cases from the elevator industry to explain how different business models are employed in connection with business and IoT ecosystems, as well as their challenges and possible options to overcome these challenges.
\end{abstract}

\section{Publication History:}

Received: April 27, 2018

Accepted: August 24, 2018

Published: August 27, 2018

\section{Keywords:}

Internet of things, Business ecosystem, IoT ecosystems, Ecosystem business model

\section{Introduction}

Many real-world Internet of things (IoT) applications have been postulated in many industries: the domain not only covers conventional industrial sectors, but also the consuming industries of everyday life, in which IoT can bring significant improvement, even leading to new business models [1]. IoT, also called the Internet of Everything or the Industrial Internet, is a new technological paradigm envisioned as a global network of machines and devices capable of interacting with each other [2]. It refers to linking the objects of the real world with the virtual world, thus enabling connectivity at any time, in any place, for anything and for anyone. It enables a world in which physical objects and beings and virtual data and the environment interact with each other in the same space and time. Enterprises can utilize IoT to create and capture value by connecting devices integrated with in-house business intelligence applications, traditional enterprise resource planning and supply chain systems, business analytics and decision support systems [3]. The true value of IoT lies in creating an environment in which the crucial information from any of the networked autonomous actors can be shared efficiently with others on a real-time or interval basis [4]. The adoption of IoT technology is rapidly gaining momentum as technological, societal and competitive pressures push firms to innovate. IoT has the potential to disrupt industries through changing products, services and business models, just as the Internet did in the 1990s [5].

IoT is a broad concept and a consensus has yet to be built concerning a common definition. This paper focuses on conventional manufacturing companies (using elevator services as case studies) expanding their new offering in providing IoT services to generate additional revenue as well as to improve productivity, which essentially can bring value to their clients and other stakeholders. In the IoT service domain, information is gathered from various sensors through networks, processed for information analytics and optimization in a central service (cloud computing) and finally suited to decision making and control of the targeted aspects. These services are expected to find users in a wide range of smart applications related to home, factories, energy, healthcare, logistics and maintenance and could revolutionize society. Especially, there are several initiatives aimed at promoting IoT services in the industry, including "Industry 4.0" in Germany, "Made in China 2025" in China, the "Industrial Internet" in the United States (US) and the "Industrial Value Chain Initiative" in Japan [6]. In particular industry 4.0 foster automation and data exchange over cyber-physical systems, internet of things, cloud computing and cognitive computing, which communicate and co-operate each other and with human in real time both internally and across organization service offered and used by actors of the value chain [7]. Hermann et al. proposed six design principles for Industry 4.0 implementation; they are interoperability, virtualization, decentralization, real-time capability, service orientation and modularity; which rely on full transparency of communication among physical things, physical and virtual network [8]. Some examples for Industry 4.0 are machine which can predict failures and trigger maintenance processes autonomously or selforganized logistics which react to unexpected changes in production, as well as services through machine to machine interface. All these effect needs everything is interlinked with everything else, it is a fair assumption of driving force behind IoT [9]. However, in the modern global, competitive and collaborative business environment, an IoT business model must be designed as a business ecosystem due to the fact that no firm owns content, networks, software and hardware in the same spectrum. Therefore, business model design considering the business ecosystem is required to bridge the gap between expected value and the firm's existing core competence or innovative capability [10].

"Corresponding Author: Chia Tai Angus Lai, Alliance Manchester Business School, University of Manchester, Manchester, United Kingdom, Antai College of Economics and Management, Shanghai Jiaotong University, Shanghai, China; E-mail: lai_ngs@yahoo.com

Citation: Lai CTA, Jackson PR, Jiang W (2018) Internet of Things Business Models in Ecosystem Context-Cases of Elevator Services. Int J Comput Softw Eng 3: 135. doi: https://doi.org/10.15344/2456-4451/2018/135

Copyright: $\odot 2018$ Lai et al. This is an open-access article distributed under the terms of the Creative Commons Attribution License, which permits unrestricted use, distribution, and reproduction in any medium, provided the original author and source are credited. 
The central elements of IoT include the concepts of the ecosystem and the business model. The business ecosystem concept was originally presented by James F. Moore in 1993 and stems from the notion that innovative businesses rely on different resources, including capital, partners, suppliers, customers, or even authoritative bodies, with which they create co-operative networks [11]. In addition to the business ecosystem as such, there are other spectrums in the IoT ecosystem environment: there are different levels of ecosystems from the technical or process perspectives, including platforms, protocol standards, cloud computing, devices and applications related to hardware and software. The business ecosystem and IoT technological ecosystem co-evolve in combination to create a commercialized business model, leading to clients' choice concerning the platform of the ecosystem.

There is a considerable body of literature articulating that IoT will enable traditional manufacturing firms to innovate in developing new business models. This literature indicates that technological advancement and product or service innovation alone may not sustain the life of a business unless a viable and sustainable business model exists. A viable business model will play an important role when it comes to leveraging the opportunities of new technological innovation, ensuring that it matures and is cost-effective [1]. However, business models based on largely static, firm-centric core competences or historical information architectures are facing challenges in today's dynamic environment as new ways of creating value arise across industries and between firms, clients and other stakeholders. Furthermore, adapting the established technologies of an industry to develop innovative products and services is ultimately the cornerstone for breakthrough business model development and embracing the business ecosystem concept when adopting the IoT technology ecosystem may facilitate novel applications and business models.

In this paper we aim to analyse the business model from both the business ecosystem and IoT ecosystem perspectives, specifically applied to new service IoT offering in elevators industry. The objective is to shed light on existing and potential models by discussing them in connection with the underlying ecosystems in designated domains. This study contributes to recent IoT business model studies, adopting the lens of the IoT ecosystem perspective, which advises firms to embrace the business ecosystem concept when designing new offerings in elevator industry in China based on IoT technology. We intend to:

1. Discuss the relationship between the business model and IoT ecosystem

2. Utilize elevator service case studies to illustrate the IoT business model in the ecosystem context

3. Describe the challenges of IoT business model development

This paper begins with a review of the theoretical foundations of business ecosystem and business models, we then construct a discussion of the IoT business model in ecosystem context based on different frameworks. This is followed by the use of real-world IoT business model cases as exemplars in the elevator industry to illustrate similar IoT technological application in the same industry based on different business model approaches under the ecosystem environment. Finally, we review our key findings and draw conclusions regarding the challenges of IoT business model development and possible solutions.

\section{Theoretical Background}

Research on business ecosystems and business models has gained attention in the literature. However, there is little extent work on the ecosystem business model concept and similarities and differences between various applications. In this section, we identify and discuss the relevant literature in the broader context of the business ecosystem and business model, as well as more specifically with regard to the business model within the ecosystem perspective. We show that the business model embedded in the ecosystem concept is especially well suited given the disruptive technological impact on business model design in recent years, whereas the earlier literature on the business ecosystem generally provides somewhat more multifaceted discussions.

\section{Business ecosystem}

The ecosystem as an abbreviated term for the ecological system in the business context is a notion derived from the biological sciences. Just as biological ecosystems consist of a variety of interdependent species, business ecosystems analogously depict interdependent networks of organization [12]. Business ecosystem theory originated in the work of Moore (1993) and illustrates that successful business must attract resources of all sorts, drawing in capital, partners, suppliers and customers to create cooperative networks. Such networks should under the rubric of strategic alliance, virtual organizations and the like nurture the complex business communities that bring innovations to market [11]. In these networks, each member contributes to the ecosystem's overall wellbeing and is dependent on other members for its survival. Reciprocally, the survival and success of each member is influenced by the ecosystem as a holistic entity that is in continuous evolution [13].

At the centre of the business ecosystem, actors in the business ecosystem co-evolve capabilities around existing or new innovations by working co-operatively as well as competitively in the creation of products and services $[11,14,15]$. Other than traditional partners, such as customers, suppliers and complementors, business ecosystems may also be seen to comprise distributors, outsourcing firms, finance providers, research institutions, regulatory authorities and standard-setting bodies, as well as to some extent competitors when their actions and feedback affect the development of the firm's own products or processes [16,17]. These loose networks of actors in the ecosystem, which together provide related products or services, as well as technological providers and a host of other organizations, are affected by the creation and delivery of the company's own offering [18]. If we analyse further, like an individual species in a biological ecosystem, each member of a business ecosystem ultimately shares the fate of the network as a whole, regardless of that member's apparent strength. However, biologists have observed that natural ecosystems sometimes collapse when environmental conditions change too radically and dominant combinations of species may lose their leadership. New ecosystems then establish themselves, often with previously marginal plants and animals at the centre. This applies to the business environment today when dealing with challenges from the economy, market, new innovation or technological breakthrough; there are clear parallels and profound implications $[11,19]$.

A number of studies have shown similar constructs to describe the ecosystem and generic products and services from the ecosystem perspective, including the "industrial ecosystem" [20],"product ecosystem" [21], "service ecosystems" [14] and "technology-based 
ecosystem" [22], or from the perspective of the specific industrial segment or the firm-based, for instance the Internet ecosystem [23], Amazon's web service ecosystem [24], Google's innovation ecosystem [25] and the automotive leasing ecosystem [17]. All these are examples of interdependent networks that centre on respective collaboration [12]. The business ecosystem has the co-evolution value of being able to account for change dynamics and the strategic implications of these changes for member organizations [11]. Through the ecosystems approach, firms can analyse either own businesses by considering their suppliers and the partners they collaborate with and at the same time assessing the strength of their competitors with respect to the ecosystems that they are able to produce. Moreover, according to Iansiti and Levien [13], the presence of hubs makes the network robust to the removal of individual nodes, as long as the hubs remain intact. In contrast, the removal of a hub often results in a collapse of the whole network. Following the biological metaphor, it is suggested that the roles in the biological ecosystem correspond to the strategies of the firms in the business ecosystem, with the most critical roles in the business ecosystem being the roles of the so-called keystone, dominator and niche player $[13,26]$.

\section{Ecosystem business models}

Consensus on a common definition of the business model has yet to be reached in the management literatures [27]. However, one early definition that has been widely influential stems from Amit and Zott [28]: "A business model depicts the content, structure, and governance of transactions designed so as to create value through the exploitation of business opportunities". Also, a business model is an organization's approach to generating revenue at a reasonable cost and incorporates assumptions about how it will both create and capture value to benefit enterprises [29]. Essentially, every company has a business model, whether it articulates it or not. However, complications arise with the most basic questions. What is a business model? What constitutes the firm's business model? Chesbrough [30] suggested that a business model performs two important functions: value creation and value capture. Similarly, Teece [31] defined the essence of a business model as defining the manner by which the enterprise delivers value to customers, entices customers to pay for value and converts payment into profit. Pavie et al. offered a good overview of various business model concepts in their 2013 paper for the ESSEC business school; no matter what market a business organization is competing in, it will - either implicitly or explicitly - create or apply a business model. A business model can be defined as the architecture and mechanism of actual value creation by an organization [32]. All these concepts have in common a focus on the rationale for how an organization creates, delivers and captures value.

More detailed frameworks for the design and classification of business models have been developed since the early publications on the topics. Teece [31] defines a business model as reflecting management's hypothesis about what customers want, how they want it and how an enterprise can best meet those needs and be paid. Gassmann, Frankenberger and Csik $[33,34,35]$ employ a conceptualization that consists of four central dimensions - the who, the what, the how and the value - in the magic triangle. By answering the four associated questions and delineating (1) the target customers, (2) the value proposition for the customers, (3) the value chain behind the creation of this value and (4) the revenue model that captures the value, a business model can then be established. Based on this magic triangle, Gassmann's St. Gallen Business Model Navigator identified
55 repetitive patterns that form the core of many new business models, having looked at several hundred business model innovators. Alexander Osterwalder [36] introduced the business model canvas in the Business Model Generation Handbook, offering a set of nine interdependent "building blocks", beginning with key partners and key activities, together with key resources, moving on to the value proposition to target the customer segment based on customer relationships and channels and ending with the cost structure and revenue streams defined by the other elements. This business model canvas aims to expand along with the sum of resources and activities which the company organizes and implements in order to provide a specific value for a particular target segment [37].

These frameworks developed appear to analyse the related challenges of innovating and implementing new business models in practice [38]. In particular, technology can bring about disruptive business model opportunities in terms of the ability to experiment and through progressive introductions of new products or services. Systematic data collection on usage and performance is important in the development of business models [30]. From another angle, challenges have also been witnessed in emerging industries with regard to technology, application and organization. It is argued that there is the need for a new business model or novel technology to connect ecosystem stakeholders and initiate a new way of commercializing the business model and technology [39]. These challenges require stakeholders to achieve interoperability between different levels of the organizations to cope with uncertainties [40,41]. Therefore, it is argued that while existing business model templates and frameworks are adequate for examining the challenges faced by single existing organizations $[36,42]$, they are less suited to analysing the interdependent nature of growth and success among companies that are evolving in the same innovation "ecosystem" [43]. Traditional industrial-era business models held that competitive advantage was based on product excellence, in-house technological innovation and careful management of scarce resources and supply chains [44]. More recent academic research suggests the need to expand the focus in business models from a single company point of view to an ecosystem perspective [45], particularly in the climate of increasing complexity, with more adaptive technical solutions and changes in the roles of business actors compared to the traditional way of managing partners to support firm-centric value design. Furthermore, companies are seeking new commercialized offerings, shifting the focus from industry-specific applications to applications spanning multiple industries; under such circumstances, the challenges increase substantially [40]. Similarly, Zott and Amit [46] defined a business model as a system of activities dependent on each other through the focal company and the surrounding network. Adopting the established technologies of one industry to develop innovative products and services in another industry is ultimately the cornerstone of a breakthrough in a new offering in today's business society, although challenges need to be overcome. In building business models for emerging ecosystems, the most critical challenges typically are not at the firm level, but lie at the ecosystem or network level and industry interfaces [47]. Changes in industry boundaries and service architectures require the development of value design from an ecosystem business model perspective. Companies are sometimes forced to work on development within a network of partners, which include their customers or even competitors. This implies not only a lead users' approach but also encompasses an entire ecosystem as a facilitator. In the digital world, the one who brings the most developers to its platform wins [48]. 
Citation: Lai CTA, Jackson PR, Jiang W (2018) Internet of Things Business Models in Ecosystem Context-Cases of Elevator Services. Int J Comput Softw Eng 3: 135. doi: https://doi.org/10.15344/2456-4451/2018/135

Page 4 of 10

\section{Ecosystem Business Models for the Internet of Things}

\section{Defining the IoT ecosystem}

The essence of IoT is the interconnection of the physical world of things with the virtual world of the Internet, software, hardware and network platform, as well as the standards commonly used for enabling such interconnections; these may become the core of an IoT ecosystem. Mazheils, Luoma and Warma [49] define the IoT ecosystem based on different focal aspects; (i) connected devices and gateways, including the hardware platform; (ii)the connectivity between devices and the Internet; (iii) the application services built based on connectivity with the common software platform; (iv) the supporting services that are needed for provisioning, assurance and security standards [49]. Within current IoT ecosystems, the number of different vendors providing the components of proprietary platforms, protocols and interfaces at different layers makes them barely compatible, while keeping the prices of such components high. Some of the available technologies could be seen as de facto standards, but no fully open standards have yet been applied successfully in the domain of sensor networking. This puts firms in a difficult situation in terms of managing IoT ecosystems when deploying them with a view to firms' common value.

Mejtoft [50] depicts three layers of value co-creation in IoT, focusing on the co-evolving value-driver perspective of the IoT ecosystem: in the first layer, manufacturing and retailers can benefit from simply tracking objects; the second layer concerns the creation of value through the collection of data that can be used in both industry- and customer-driven value creation; the third layer relates to co-creative IoT partners and value creation at different levels of the IoT ecosystem, with value capture and creation as two main elements of business model constructs. Chan [51] present a more detailed four-layered architecture of IoT in explaining the ecosystem environment from a technical perspective: object sensing and information gathering - the use of smart devices to collect contextual information concerning the environment; information delivery - wireless technology networking; information processing - pervasive services providing big data analytics capability with mostly cloud computing; application and smart service - heterogeneous network performance and computing capability to accommodate users' requirements in support of decision making.

The major challenge for IoT projects in realizing business potential lies in the integration of multiple businesses operating in a collaborative environment. Companies should focus on analysing the business system and its stakeholders [52]. There are many innovative IoT projects that start with a rather unclear or unfocused development track. For many projects, there is no problem engaging in new pervasive information system development, but there is a problem combining this with a new value proposition in such a way that the innovative idea is clear to all stakeholders and allows their own assessment from the profitability and technological feasibility perspectives $[53,54]$.

\section{The IoT ecosystem business model}

Smart objects in IoT facilitate novel applications and business models; however, designing a viable business model requires the collection of data automatically and remotely from devices and turning these data into useful information then helps to solve problems and enables the development of embedded services and a revenue model [45]. The nature of IoT technology enables the pooling of resources in networks that include multiple nodes and links between the nodes. This means that there are almost endless ways to utilize information and IoT infrastructure [55], Bucherer and Uckelmann further elaborate that information exchange between the nodes in an IoT network and the involvement of all stakeholders in the "win-win" information exchange are the key elements in designing an IoT business model. Therefore, the IoT business model should shift from a cost-centric approach to a value-focused perspective, i.e. from a firm-centric to an ecosystem approach. Fleisch et al. [48] further emphasize that IoT bundles diverse technologies and systems together by combining technologies and functionalities. A complex product or service from smaller subsystems can be designed and built independently. This enables a shift in power in the steps that can be executed at the network edge, which enhances the modularization of business processes and empowers decision making in a decentralized manner.

Leminen et al. [45] posit that the central elements of IoT include the concepts of the ecosystem and business model. A framework connecting the various types of IoT business model is built based on the underlying ecosystem; there are two principle axes, the first defining the type of ecosystem from closed and private to open networked and the other the type of customers from business to consumer. In this regard, more mature industry tends to apply a more closed ecosystem and immature industry and newcomers will apply a more open ecosystem. Equally, consumer products tend to favour a more open ecosystem in order to gain platform leadership advantage. Ju, Kim and Ahn [56] also further note that IoT ecosystems are changing from closed private ecosystems to open networked ecosystems. Among the examples they use are that Car2Go services are provided to consumers through a closed private ecosystem, while products and services provided by Google and GE work on open and integrated ecosystems. Nest is trying to make the Nest learning thermostat the centre of smart homes. Home appliances, such as smart light bulbs, tend to be fragmented and controlled by separate applications. As part of an open networked ecosystem, the Nest developer program enables various home appliances, such as lights and washers, to interact with the Nest learning thermostat. By making connections between various appliances, Nest can provide consumers with a seamless and personalized experience. Integrated services reframe the products and services of companies and offer far greater value for consumers [56]. However, the degree of openness depends on the maturity of the ecosystem.

Rong et al. [39] developed an integrated 6C framework to improve understanding of IoT-based business ecosystems, namely context, cooperation, constructive elements, configuration, capability and change. The context concerns the environmental setting for ecosystem development, co-operation reflects the mechanisms by which the partners interact to support strategic objectives, constructive elements define the fundamental structure and supportive infrastructure of the ecosystem, configuration seeks to identify the external relationships among partners and capacity investigates the key success features of a supply network from the functional view of design, production, inbound logistics and information management. Finally, each business ecosystem faces the challenge of change [39]. Rong et al's case studies reveal that the ecosystem tends to be very open at an early stage, in which the focal firm needs more stakeholders to add value to products or the service platform. The focal firm primarily controls the 
product or service during the business model development stage, but then needs partners (including customers and suppliers) and other third parties to provide support or make modifications, thus refining it with more functional features in the complex IoT environment. Once the ecosystem begins to mature, the focal firm will consider the product/service as a dominant design, suggesting the development of any new business model should be adaptable via an open platform and enabling diverse solutions to allow full utilization of participants resources and capabilities [51].

We argue that regardless of how sophisticated the IoT business model a company would like to deploy, it will evolve more or less differently depending on partners from both the technical and business perspectives; therefore, the core of an IoT ecosystem concerns the interconnections between the physical world of things and the virtual world of the Internet, software, hardware and cloud computing platforms, as well as the standards commonly used for enabling interconnection [49]. From the business ecosystem perspective, we argue that the leadership of companies will have a strong influence over the co-evolutionary processes: the operation of the system cannot be understood by studying its parts detached from the entity. Thus an IoT ecosystem of co-creating actors is established: essentially, every actor in this IoT ecosystem needs a distinct business model itself to serve its clients and all actors together co-exist and share the value that the final customer is willing to pay. Therefore, firms need to reposition themselves when designing business models for IoT due to the fact that an ecosystem business model is a business model composed of value pillars anchored in ecosystems and focuses on both the firm's method of creating and capturing value and any part of the ecosystem's method of creating and capturing value [57]. In summary, we conclude that a viable business model for IoT should change its focus towards an ecosystem approach to doing business and if it uses business model design tools that consider the nature of the ecosystem of the IoT rather than emphasizing an individual company's self-centred objectives, it will move towards a common ecosystem goal instead of different goals for each of the stakeholders in the ecosystem.

\section{Proposed IoT ecosystem business model design framework}

Leminen et al. [47] proposed an ecosystem perspective on business models to help understand possible IoT business models and challenges in building them. Their value design framework comprises four pillars: value drivers, value nodes, value exchanges and value extracts. Both a firm's business model and any part of the ecosystem business model can be described in terms of value design, a concept that illustrates how value is deliberately created and captured in an ecosystem with the four value pillars anchored in the ecosystem [57, pp. 9-11] as follows:

1. Value drivers express the individual and shared motivations of diverse participants to fulfil a need to generate value, realize innovation and make money.

2. Value nodes include various actors, activities or processes.

3. Value exchanges are flows that describe the exchange of value through different resources, knowledge and information.

4. Value extracts refer to the parts of the ecosystem that extract value. This concerns the meaningful value that can be monetized and the relevant nodes and exchanges that are required for value creation and capture. Value extracts make it possible to "zoom in" and "zoom out" in the ecosystem to focus on something beneficial for the business.
In our following case studies, we employ this four-pillar value design framework to analyse business models in the IoT ecosystem, based on multiple case studies in similar ecosystems in the same industry using IoT to offer business models in different ways.

\section{Case Studies}

The qualitative analysis undertaken in this research was based on a multiple case study research approach in which three companies in the elevator industry in China were chosen. The three companies/ cases selected have all adopted advanced IoT technology in their new service-oriented offering, embedding an IoT ecosystem at different levels and commercializing under new business models in a different manner. These cases represent exceptionally interesting examples that illustrate the importance of embracing the ecosystem business model from different angles, as well as the distinct challenges inherent in the IoT ecosystem business model. In investigating these three cases, we adopt the four-pillar value design framework (Figure 1), explained in the previous section, to analyse the value drivers anchored in the IoT ecosystem in order to create and capture value through establishing the business model.

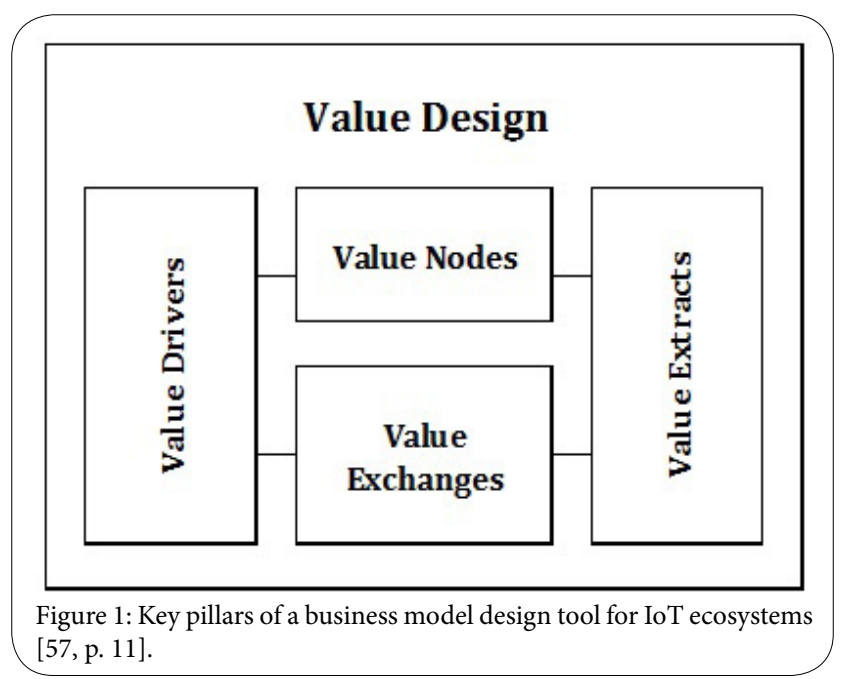

The data for this research were collected mainly through a series of semi-structured interviews with the three companies' executives and IoT project leaders. To gain an overview of the entire IoT ecosystem business model, we also interviewed experts from related IoT vendors, including hardware and software providers, portal application developers and cloud service providers, most of them located in China. Furthermore, in within the spectrum of the Chinese elevator industry, authoritative bodies, including government bodies and industrial associations, with a strong influence on the industry and regulation were also interviewed in order to gain a broader view of the studies. In addition to interviews, secondary sources of data were accessed, including companies' public information and exemplar cases demonstrated in their public documentation and websites.

The interviews were conducted as open discussions rather than in the reactive structure of an interview style, starting from asking about participants' roles in the overall IoT design, then about their key contributions and the underlying challenges in this ecosystem, gradually moving from the technical to the more commercialized aspects that are the main drivers of business model design. The interview questions included but were not limited to: (1) What are the main value drivers of the IoT offering in elevator services? (2) Who 
should be the main beneficiaries in the underlying IoT ecosystem? Who should pay for it? (3) Who are the key actors and what are the key elements or processes when designing an IoT offering for elevator services? (4) What are the challenges related to the IoT ecosystem and business model that might illustrate future trends and development?

\section{Case background and analysis}

IoT has attracted the attention of actors in the technology and business communities, who are eagerly waiting for its potential finally to be unleashed. In the Chinese elevator industry, seemingly every elevator company has started to introduce IoT offerings focused on connected services for remote monitoring or advanced services. In our case studies, three companies were selected that are aggressively adopting an IoT ecosystem; they have certain commonalities and differences in terms of technology and platforms, as well as degrees of similarity and differentiation in their ecosystems. However, each company has adopted a slightly different approach to IoT business model development based on its own beliefs concerning the specific value design drivers for its clients and society.

Company A is a global leading European-based company that provides solutions for the installation, maintenance and modernization of elevators and escalators. This company has a strong presence in China. In addition to manufacturing elevator equipment in China, the company is aggressively expanding its service business by providing corrective maintenance (on-call services), preventative maintenance (regular interval services) and major repairs and retrofits, all the way up to a full replacement service at the end of the equipment's useful life cycle. The company has a very strong own equipment installation operation nationwide, which is the basis for service opportunities. Therefore, the company is aggressively looking for opportunities to expand its service offering and IoT provides an excellent match in terms of testing the new business model and gaining sustainable competitive advantage. Company A chose to work with a prestigious global IoT and cloud computing player as a major partner from the co-creation of value perspective, developing working relationships and tailoring a Chinese-specific elevator service solution together with local partners; hence, this is a joint effort on the part of the IoT ecosystem to create a new business model. The expected benefits include the generation of new revenue by providing real-time remote monitoring, establishing safety alerts, progressing towards more advanced predictive maintenance services and supplementary benefits covering own spare parts promotion and productivity improvements. Plus, the firm aims to develop a lock-in business model to maintain long-term relationships with customers as a co-creation value driver, in particular providing tailored services to building owners to protect future opportunities concerning major repairs and the full replacement of equipment. This new service offering is targeted at a particular segment, namely those customers who have installed the company's equipment (installed base), irrespective of whether they have scheduled service maintenance under the company's own service contract, or whether their elevators are maintained by other thirdparty service providers.

Company B is a strong Chinese elevator brand, mainly focused on equipment manufacturing. The majority of the firm's equipment is sold through a distribution channel which entails selling equipment to distributors and services and repairs subsequently being provided by the same distributors. Company B was initially not overly focused on building its own resources and capabilities to service and repair its own machines for several reasons: first, selling the equipment was profitable for a long time, but over the last two years the market price has fallen dramatically; second, China has a famous and strong tradition in building factories globally and Chinese companies have thus focused their attention on manufacturing products, which has been a sound dominant logic [58]; third, the service market is fragmented in China and there is a considerable number of third-party service companies, meaning that the market is very competitive and it is difficult to make substantial profits over the short term - a clear long-term service business strategy needs to be established; finally, labour costs have been increasing over the years, but it is difficult to push service prices higher, making services unattractive from the Chinese company perspective. Nonetheless, the company still initiated an IoT offering working with local stakeholders, strategically expecting to adopt an open platform that would attract distributors to utilize this platform to better serve their customers through the basic functions of remote monitoring, safety alerts, spare parts ordering, equipment health checks and basic equipment quality diagnosis. The technology is limited to equipment design, for instance sensors and detectors built into the elevator drive, inverter and control. By installing a transmitting device, information read from the controller can be transmitted remotely through the cloud to perform remote monitoring and equipment health checks, as well as enabling standard five-party communication (voice and video) capability remotely. As an outcome, the company will have a better product portfolio to push more sales of equipment.

Company $\mathbf{C}$ is a well-known Chinese listed company specializing in industrial controls and drives. It is one of the major elevator component suppliers for integrated elevator control solutions, rather than being a traditional "elevator" company. Although it has a wide range of products, from controls and drives to standard industrial automation products and industrial sensors and detectors, the majority of its sales comes from providing integrated control systems to original equipment manufacturers (OEMs) of elevators, both to domestic Chinese companies and those with a global presence in China. In recent years, the firm has proactively provided industrial IoT solutions to the elevator, automobile and crane segments. The company vision is to build an industrial control and IoT standardized protocol with support from the "Made in China 2025" policy. In the elevator segment, drive and integrated control solutions are the centrepiece of elevators as a whole. The company is building a standard IoT platform together with its own control system. It is specializing to penetrate the elevator market together with its sub-contractors and service partners, particularly with regard to upgrades, full replacement and the major repair market. Its business model focuses on IoT as a central element with an open standard platform aimed at persuading customers to upgrade their elevators, while outsourcing other mechanical components (elevator machines, cars, ropes and landing doors) directly from an elevator components company. It is now very aggressive in penetrating the elevator market. The main driving value for this company is to utilize the IoT and elevator ecosystem fully in building a standard operating platform business model from an entirely different angle; although it does not produce elevators in its factories, the target is to establish itself as an industrial leading IoT platform provider.

\section{The IoT elevator service offering and ecosystem}

As described earlier, although these companies may adopt slightly different approaches to the IoT business model based on their own beliefs concerning the specific value design drivers for their clients and society, there are some common value drivers in promoting 
Citation: Lai CTA, Jackson PR, Jiang W (2018) Internet of Things Business Models in Ecosystem Context-Cases of Elevator Services. Int J Comput Softw Eng 3: 135. doi: https://doi.org/10.15344/2456-4451/2018/135

Page 7 of 10

elevator IoT services constituting the key factors for which actors in the ecosystem are willing to pay:

1. Better end-user satisfaction and fewer complaints

2. Maintaining the value of assets and prolonging the useful life of equipment

3. Improving public safety

4. Attaining better transparency in equipment operation information

\section{Value drivers}

In terms of value drivers, there are more specific services that each company claimed their clients should benefit from over traditional scheduled maintenance, termed corrective maintenance or reactive maintenance (reference), as follows:

1. Real-time remote monitoring of elevator equipment

2. Earlier fault detection and alerts on a real-time basis

3. Enhanced instance service technician dispatch

4. Provision of basic preventive maintenance, repairs or parts replacement through constant equipment health checks

5. Offering voice or video communication at remote locations

6. Provision of operation analysis and regular reports to all related parties in the business ecosystem through a mobile device portal or direct interface.

7. Implementation of user portals to enable clients to understand equipment performance in order to prolong the asset life cycle

\section{Value nodes - IoT ecosystem}

In our case studies, the elevator IoT service offering was divided into two categories of value nodes. The IoT ecosystem is formed around commonly used IoT hardware, software, platforms and standards, based on which the definition of value nodes for actors and activities can be described as follows:

1. Data collection device: installed in elevator equipment and connected directly to an integrated control box; this contains a $2 \mathrm{G} / 3 \mathrm{G} / 4 \mathrm{G}$ carrier signal that is responsible for transmitting data (including voice/video) to a data centre on a real-time or interval basis.

2. Telecom carrier: an independent mobile carrier that can help transmit data through wireless form.

3. Cloud services, cloud computing and Big Data analysis: once data are collected in the cloud, certain data modelling and analysis need to be performed to convert the data into useful information for further action and analysis; some partners at this point start applying artificial intelligence (AI) or cognitive capabilities.

4. Shared information portal: a user-friendly portal needs to be designed to allow different shared information sets to be tailored to meet different stakeholders' requirements; the portal can be accessed directly through the cloud or through a physical data server.

5. Remote monitoring centre: a centre that contains all the necessary information for decision making and follow-up actions; this centre may also be responsible for machine-to-machine (M2M) management, network management and service management. In our cases, two companies are using such centres, which also perform as 24/7 call centres in which traditional phone calls can be managed through help-desk staff.

6. Mobile devices: for service technicians receiving/sending communication information through a remote monitoring centre, the centre can send a job site equipment status report, possible fraud information, advance tips for repair/maintenance of equipment, earlier spare parts ordering and regular e-learning training and safety tips. This device can also keep track of service timing records, required for ad hoc inspections and annual equipment certification issuance by the relevant authorities.

\section{Value nodes - business ecosystem}

This defines business stakeholders, including suppliers, partners, authoritative bodies and possible competitors. In our IoT offering cases, they are the following:

1. OEMs: the OEMs manufacture elevator equipment and install it at the client's site. They may or may not be the party providing a warranty and on-going regular maintenance and repair. However OEMs normally hold the main responsibility for any possible design or component default during the life span of equipment.

2. Authoritative bodies: these include the General Administration of Quality, Supervision, Inspection and Quarantine (AQSIQ), which is the authority setting up quality standards, issuing certificates and regulating inspection criteria. For instance, the standard GBT24476-2017 for the "specification for internet of things for lifts, escalators and moving walks" was published together with the National Standard of the People's Republic of China and clearly defines the standards, guidelines and regulations for elevator IoT. The other semi-authoritative body is the China Elevators Association (CEA), which plays an important role as the bridge between the elevator industry and the government.

3. Third-party independent service companies: independent service companies provide regular maintenance, repairs, upgrades and full replacements of equipment. Most OEMs also have their own service arm to provide on-going servicing and repairs.

4. Facility management companies: these are companies that safeguard building management and ensure all equipment operates effectively and safely. In most cases they are the direct customers of OEMs and service companies, meaning that they receive the value of IoT services and pay the bills.

5. End users: these are the passengers who use the lifts. The equipment has to be operated effectively and efficiently to move them from one location to the other, safely and in comfort.

6. IoT solution vendors: as described in IoT ecosystem, there are different levels of IoT solution vendors, including hardware, software, cloud computing, Big Data analysis, portal design and system integration providers.

Value exchange - flow of knowledge and information among different resources

During the interviews, all three companies demonstrated a basic standard in terms of IoT offerings, as shown in Figure 2. Machines can communicate with machines without human intervention, i.e. between elevators and the cloud, employing cloud computing and data analysis to identify potential fraud, issue alerts and suggest corrective 
Citation: Lai CTA, Jackson PR, Jiang W (2018) Internet of Things Business Models in Ecosystem Context-Cases of Elevator Services. Int J Comput Softw Eng 3: 135. doi: https://doi.org/10.15344/2456-4451/2018/135

Page 8 of 12

actions. They can then trigger follow-up actions, potentially sending service technicians on site with parts and repair tips in advance. At the same time, the user portal can have visibility over machine movement before and after the corrective actions. There are no major differences in the flow of value exchange; rather, the key component is the way in which each company deals with the data collected, utilizing data from certain identified patterns to make decisions. This relates to the major competences the company can exploit to take a leading advantage over others and the key elements of business model value drivers.

\section{Value exchange - summary}

Figure 3 presents a summary showing the complex network of activities that needs to be co-created with different stakeholders: vendors, other service providers, customers or authoritative bodies. These stakeholders participate in the overall IoT service offering collaboratively and are not limited to just value in exchange (paying the bill in exchange for a service) or value in use (who will use the service); they also need to receive relevant shared information, mostly through real-time applications, for decision making and action in their own networks and value design needs to be co-created to ensure value can be exchanged so that all actors benefit regardless of value.

\section{The IoT ecosystem business model: value extracts}

Our empirical study reveals different levels of ecosystem business models. The large company is more mature and has driven the development of IoT due to its plentiful resources, benefiting from key roles in its comfort zone as well as core competences developed over decades. Thus, it tends to have a more closed ecosystem and focuses on its core competences together with strong partners in terms of technology provision to provide a closer and more sustainable business model with a view to long-term benefits. However, usercentred approaches, which mean opening up innovations and the
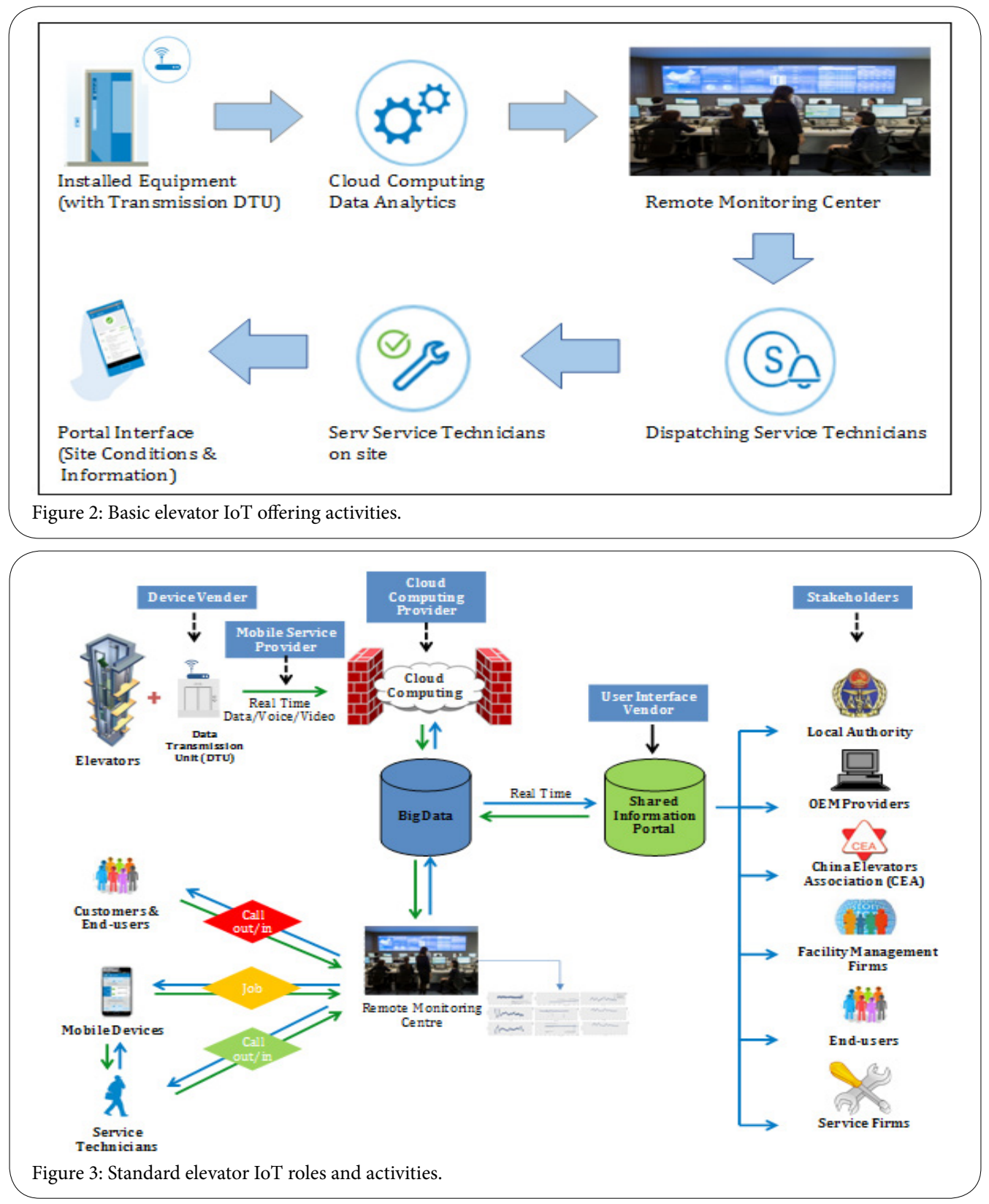
Citation: Lai CTA, Jackson PR, Jiang W (2018) Internet of Things Business Models in Ecosystem Context-Cases of Elevator Services. Int J Comput Softw Eng 3:

ecosystem, should be utilized when creating IoT business models [42], particularly in the area of co-creative value, in order to provide tailoring to customer-specific requirements. The mid-sized or relatively small immature company has adopted a more open ecosystem with an open IoT protocol in order to create a society embracing a standard that will attract more actors to join its ecosystem, believing that this will eventually be of real benefit to clients and end users. However, there are still challenges in the ecosystem business model; rather than concerning technology, these relate to how to commercialize and make a profit if the system is open and any actors inside or outside the ecosystem can play their role and go downstream or upstream to penetrate market share.

Company A plays is a keystone actor in its ecosystem [44,59], expecting to consolidate the industry competence around the value proposition by providing a dominant design or architecture that facilitates collaboration and aids collective innovation in the business ecosystem. It promotes customized, connected services within a system that uses the sophisticated platform of a global partner with AI capability to process data from elevator monitoring devices in the cloud, analysing and predicting equipment problems before they occur. For this solution, clients will need to pay a monthly fee, deriving the value of enabling preventive maintenance to minimize downtime and repairs, utilizing a smart solution to minimize the number of unplanned stops and maximizing the life cycle of the installed equipment. This has advantages compared with traditional calendar-based elevator maintenance, with various components serviced or parts replaced based on estimated times of wear and tear. The intention is to attain revenues and profits through better service provision and the promotion of proprietary spare parts, system upgrades, major repairs and ultimately full replacement of equipment at the end of useful life.

Company B has adopted a more open IoT ecosystem as the majority of its business is with distributors - the actors providing services to the clients. The company is fully utilizing its commercial resources (resources available in the market) and standard components to construct a simple and straightforward IoT connected service and provide this as a product feature sold together with elevators. This is a cost-effective solution which will benefit the distributors (partners) and eventually end users. The business model is more inclined towards traditional product sales, collecting additional fees from clients to acquire this service upfront on a one-time basis. One of the critical factors is how data are collected and shared.

Company $\mathrm{C}$ believes that data should be shared openly through the entire ecosystem, including business partners and technical partners; it is up to each of these actors to decide how to use the data for their own benefit. Company $\mathrm{C}$ is essentially not an elevator company, but a supplier of integrated control components to elevator OEMs. It has significant market share in providing elevator control systems to full elevator OEMs and it thus makes sense to provide an IoT solution which utilizes the control systems installed by these elevator companies. The majority of IoT devices read from standard sensors and detectors already installed in every part of the elevator system, including landing doors, machinery and signal systems; the control system is at the heart of collecting all data. With this benefit, companies just need to have a reading device attached (built in) to their control system and transmit data to the central remote monitoring service. It is intended to build an open elevator IoT platform and provide services to the entire elevator ecosystem, including manufacturers, service companies, facility management companies and authoritative bodies. The company provides the IoT transmission device free of charge as it is already built into the control system; the model is to provide tailored data modelling and analysis capability for data collected and stored in the company's data centre; in other words, the value driver is selling data and services rather than promoting hardware. The company believes with increasing amounts of data, the services provided will be of more use to each actor in the ecosystem. These services include remote monitoring, safety alerts, parts ordering, a service technician dispatch system, a friendly portal tool and preventive maintenance services. From our interviews, the firm also lobbies authorities for the use of the IoT platform as a standard interface city by city, meaning that any elevator service company wishing to do business in these cities will have to buy their service, or at least interface with the local authority safety monitoring system which is part of China's vision for smart cities.

In summary, we employ Westerlund et al's [57] key pillars of business model design as a tool for IoT ecosystems to illustrate the differences between these case companies in Table 1 .

\begin{tabular}{|l|l|l|l|l|l|}
\hline Company & Type of Business Model & Value Drivers & Value Nodes & Value flows/exchanges & Value extracts \\
\hline $\begin{array}{l}\text { A: Global } \\
\text { elevator } \\
\text { player }\end{array}$ & $\begin{array}{l}\text { Promote IoT offering as } \\
\text { advanced service offering }\end{array}$ & $\begin{array}{l}\text { Provide advanced } \\
\text { elevators service and } \\
\text { predictive maintenance } \\
\text { over traditional } \\
\text { maintenance }\end{array}$ & $\begin{array}{l}\text { Partner with strong } \\
\text { global IoT solution } \\
\text { provider, customers } \\
\text { and all level of } \\
\text { stakeholders }\end{array}$ & $\begin{array}{l}\text { Convert data into } \\
\text { useful decision flow } \\
\text { to stakeholders and } \\
\text { promote customized } \\
\text { predictive maintenance } \\
\text { service }\end{array}$ & $\begin{array}{l}\text { Provide unique } \\
\text { advanced elevator } \\
\text { condition base } \\
\text { maintenance with } \\
\text { monthly subscription } \\
\text { charge }\end{array}$ \\
\hline $\begin{array}{l}\text { B: Strong } \\
\text { elevator local }\end{array}$ & $\begin{array}{l}\text { Additional remote } \\
\text { monitoring feature for } \\
\text { equipment offering }\end{array}$ & $\begin{array}{l}\text { Additional feature and } \\
\text { functionality in their } \\
\text { standard equipment to } \\
\text { support distributors }\end{array}$ & $\begin{array}{l}\text { Various IoT vendors } \\
\text { (software and } \\
\text { hardware), elevator } \\
\text { distributors and } \\
\text { authoritative bodies }\end{array}$ & $\begin{array}{l}\text { IoT function attached } \\
\text { to equipment flow }\end{array}$ & $\begin{array}{l}\text { Selling equipment with } \\
\text { build in IoT feature }\end{array}$ \\
\hline $\begin{array}{l}\text { C: Elevator } \\
\text { components }\end{array}$ & $\begin{array}{l}\text { IoT platform provider } \\
\text { together with integrated } \\
\text { elevators control } \\
\text { components }\end{array}$ & $\begin{array}{l}\text { Promote data } \\
\text { modeling and service } \\
\text { to tailor customers } \\
\text { service requirement }\end{array}$ & $\begin{array}{l}\text { OEM elevator } \\
\text { manufacturers, } \\
\text { service company and } \\
\text { authoritative bodies }\end{array}$ & $\begin{array}{l}\text { An IoT open platform, } \\
\text { centralized database, } \\
\text { information and money } \\
\text { exchange }\end{array}$ & $\begin{array}{l}\text { Establish IoT open } \\
\text { platform to promote } \\
\text { data analytical service } \\
\text { to tailor needs from } \\
\text { clients }\end{array}$ \\
\hline
\end{tabular}

Table 1: case summary of extractions in value design in the IoT ecosystem business model. 


\section{Challenges of the IoT Business Model in the Ecosystem Context}

Based on our research on IoT business model design in the ecosystem context in three different types of elevator companies in China, we conclude that there are various opportunities and challenges in the ecosystem from both the technical (IoT ecosystem) and business (ecosystem business model) perspectives. During the interviews, we realized that to address challenges in building the ecosystem business model within the IoT ecosystem environment, it is first necessary to distinguish whether the challenges are at firm level, i.e. constituting elevator contextual factors, or at the IoT ecosystem system level, more specifically on creating value that customers will be willing to pay for from the firm's existing core competences, IoT networking or the surrounding ecosystem. We concluded that in building the IoT business model, the most critical challenges typically are not at the individual firm level, but at the ecosystem and industry interfaces.

1. One of biggest challenges found in relation to IoT business models in other industries lies in how to proceed from promises to reality [47], namely how to turn promising sounding IoT technology into a real-life business model. IoT will provide a breakthrough only if and when customers attain clear and concrete benefits and hence the business model can be monetized. In our case studies, all the companies had solid business applications attached to existing firm-centric core competences, but challenges remained in terms of ensuring clients and different level stakeholders would be willing to pay for the value they perceive as expected. The three companies approached the commercialization of IoT solutions from different angles based on their surrounding ecosystems. However, IoT is a relatively new solution and there are no definitive answers to which model gains better acceptance from customers; hence all three companies agreed that there was still a need for trial-and-error adjustment in testing market acceptance. One of the solutions to overcome this challenge is to have value design tailored to customers' specific needs based on value co-creation with stakeholders.

2. IoT is moving into a relatively new area, shifting from traditional industry with a product focus to service-centric industries, of which the elevator industry is a good example. These companies have maintained their firm-centric perspective for decades or even more than 100 years and may not have expertise in IoT ecosystem technology and management. Hence, shifting their focus from the firm business model to an ecosystem business model could be a challenge for them, regardless of which commercialization strategy they employ. We argue that existing business model templates and tools are not well suited to the interdependent nature of companies that are evolving in the same ecosystem, because they have been designed to address the challenges faced by single incumbents [60]. All three companies encountered challenges in terms of how to integrate the business network at the ecosystem level rather than drawing on their own firm-centred competences. Therefore, our perspective on the value design ecosystem business model becomes critical to overcome these challenges. Companies have to align each actor within the business ecosystem towards a common goal or direction, rather than each pursuing a different direction. To overcome this, common value extraction during value design becomes critical when designing the business model. The dominant actor has to be open to accepting expert views from different areas instead of insisting on its own firm-centric view.
3. Both providers and customers in emerging IoT ecosystems are still seeking to identify their roles and underlying value drivers. It seems that IoT vendors in the ecosystem are becoming aware of the fact that increased networking and cooperation with multiple stakeholders, including partners, customers and end users are needed to overcome the barriers to the emerging platform. The entire value-creating network should be involved in developing customer-oriented services, not only as those who pay for it but also as related stakeholders.

4. Data can be collected from the main control box in elevators with a few dozen sensors and detectors pre-installed in the standard elevator. These data are then sent to the cloud on a real-time basis and the real challenges arise when analysing and finding useful patterns in the immense volumes of data gathered. IoT is a popular buzzword, but in terms of linking data into the cloud, the prospects only become really exciting when applying some intelligence to it, otherwise the amount of data has little meaning. The single most important element of the IoT ecosystem is to ensure data flow and hence the exchange of value at different stakeholder levels. Identifying how data can be converted into useful information for further action or decision making still remains a major challenge. In particular, company A expects to advance elevator services towards a more predictive maintenance basis, which depends on the accumulation of data over time, sophisticated data modelling, plus the latest AI machine-learning technology. This capability is probably the most valuable driver in ensuring benefits for customers and society, but we believe this still in the early stage and needs time to develop.

5. One of the value drivers that all three companies identified concerned remote access to real-time data (including voice and video), so that a remote monitoring centre located hundreds of miles away can instantly detect problems, for instance trapped passengers, and manage urgent situations from a safety perspective as the top priority. This is also the most critical requirement from the authorities' lens. In reality, signal transmit over mobile access point name (APN) network for data is economic and affordable and can enable the cloud to signal an alert for any possible major system breakdown and trapped passengers. Voice over carrier costs more, but the costs can be accepted if only for urgent usage. However, for video service that may cost much more and thus real-time twenty four hours seven days video monitoring may not be feasible from the cost-benefit angle. Therefore, all three companies treat it as an optional service, based upon client's decision, until either carrier cost can be significant reduced or faster speed mobile network.

6. There are also challenges in determining whether the standardization of the service interface is needed for an elevator IoT platform, although China has published a new standard (GBT24476-2017) in this regard. However, customers' needs are becoming increasingly heterogeneous [47] and value cocreation differentiating services tailored to customer-specific requirements is critical for the business model. Moreover, the elevator industry is typically a business-to-business (B2B) field, rather than focusing on consumer products. The question then is whether a standardized IoT platform and service is critical to differentiate the business model. Companies A and C have taken a totally different stance on open or closed networks, each having its own angle in terms of the business model. In a niche industry, it is arguable whether the trend towards open platforms 
Citation: Lai CTA, Jackson PR, Jiang W (2018) Internet of Things Business Models in Ecosystem Context-Cases of Elevator Services. Int J Comput Softw Eng 3: 135. doi: https://doi.org/10.15344/2456-4451/2018/135

Page 11 of 12

and platform providers will eventually win, as proposed by the literature [45].

\section{Conclusion}

This paper explores the way in which firms nurture the business ecosystem to deal with the emerging IoT ecosystem business model. Three implications are highlighted in our empirical study as underlying inspiring a wealth of new business models, which frequently involve diverse partners and increasingly cross-industry ecosystems [61]. Thus, innovations in this area predominantly present an ecosystem and cross-industry orientation in contrast to the traditional industryspecific incremental innovation. Therefore, we argue that existing methods of business modelling are not sufficient in addressing the IoT ecosystem. We suggest that firms have to shift their thinking from the single firm business model of innovation to the ecosystem business model when innovating new offerings in the IoT field.

Second, through case study expert interviews and the literatures review, we realized the most critical element of the IoT business model concerns data analytic capability, especially moving from relational data modelling to AI cognitive capability, this particularly critical to our cases in elevators service segment. Data are collected on a real-time basis and modelling methods are improving all the time, so the more data collected, the better services can be defined. These capabilities heavily rely on working with both technical and busienss ecosystem over traditional firm centric core competence. The analytics engine is self-learning, so the various kinds of connected services will definitely come into play to a greater extent in the future. Elevators IoT service business model is turning from selling traditional maintenance services to selling safety, right comfort together guaranteeing minimal downtime, this is an interesting vision for IoT elevator services and further research with practical experiment is needed to accommodate future trend.

Third, all these companies have adopted the IoT ecosystem to provide service-oriented solutions to clients and other stakeholders, including enabling the remote monitoring of the operation of elevators, shortening the dispatch time of service technicians on site and providing predictive maintenance, which can alert operators to the potential malfunction or failure of components in advance in order to reduce the damage of downtime, as well as facilitating instant spare parts replenishment. All these value drivers are mutual and co-created; this not only involves the company and clients, but also different levels of the IoT ecosystem and multiple stakeholders, including authoritative bodies, from the business perspective by linking company and clients at both the M2M level and the business relationship level. This entails both human and machine learning among stakeholders to ensure the continuous improvement of value for all stakeholders in the ecosystem; in this regard, deeper serviceand customer-oriented thinking is required.

\section{Funding}

This research is supported by the National Natural Science Foundation of China \#71531010 and \#71325003.

\section{Competing Interest}

The authors declare no competing interest. ecosystem business models in the IoT field. First, IoT in general is

\section{References}

1. Lai C T, Jackson P R, Jiang W (2016) Shifting Paradigm to ServiceDominant Logic via Internet-of-Things with Applications in the Elevators Industry. Journal of Management Analytics 4: 35-54.

2. Lee I, Lee K (2015) The Internet of Things (IoT): Applications, Investments, and Challenges for Enterprises. Business Horizons 58: 431-440.

3. Bradley J, Barbier J, Handler D (2013) Embracing the Internet of Everything to Capture Your Share of $\$ 14.4$ trillion. White Paper, CISCO

4. Yang L, Yang S H, Plotnick L (2013) How the Internet of Things Technology Enhances Emergency Response Operations. Technological Forecasting and Social Change 80: 1854-1867.

5. Keskin T, Kennedy D (2015) Strategies in smart service systems enabled multi-sided markets: business models for the Internet of Things. 48th Hawaii International Conference on System Sciences (HICSS). IEEE.

6. Uchihira N, Ishimatsu H, Inoue K (2016) loT Service Business Ecosystem Design in a Global, Competitive, and Collaborative Environment. Portland International Conference on Management of Engineering and Technology (PICMET): Technology Management of Social Innovation.

7. Wollschlaeger M, Sauter T, Jasperneite J (2017) The Future of Industrial Communication: Automation Networks in the Era of the Internet of Things and Industry 4.0. IEEE Industrial Electronics Magazine 11: 17-27.

8. Hermann M, Pentek T, Otto B (2016) Design Principles for industrie 4.0 scenarios. System Sciences (HICSS). 49th Hawaii International Conference, IEEE.

9. Sarvari PA, Ustundag A, Cevikcan E, Kaya I, Cebi S, et al. (2018) Technology Roadmap for Industry 4.0. Industry 4.0: Managing The Digital Transformation. Springer Series in Advanced Manufacturing. Springer, Cham.

10. Mäkinen SJ (2014) Internet-of-Things Disrupting Business Ecosystems: A Case in Home Automation. IEEE International Conference on Industria Engineering and Engineering Management, IEEE Conference Publication.

11. MooreJ F (1993) Predators and Prey: A New Ecology of Competition. Harv Bus Rev 71: 75-83.

12. Mäkinen SJ, Dedehayir O (2012) Business Ecosystem Evolution and Strategic Considerations: A Literature Review. International Conference on Engineering, Technology and Innovation, Munich, Germany, IEEE Conference Publications.

13. Iansiti M, Levien R (2004) Strategy as Ecology. Harvard Business Review 82: $68-78$

14. Lusch RF (2010) Reframing Supply Chain Management: A ServiceDominant Logic Perspective. Journal of Supply Chain Management 47 14-18.

15. Teece DJ (2007) Explicating Dynamic Capabilities: The Nature and Micro-Foundations of (Sustainable) Enterprise Performance. Strategic Management Journal 28: 1319-1350.

16. Adner R, Kapoor R (2010) Value Creation in Innovation Ecosystems: How the Structure of Technological Interdependence Affects Firm Performance in New Technology Generations. Strategic Management Journal 31: 306333.

17. Pierce L (2009) Big Losses in Ecosystem Niches: How Core Firm Decisions Drive Complementary Product Shakeouts. Strategic Management Journal 30: 323-347.

18. Iansiti M, Levien R (2004) The Keystone Advantage: What the New Dynamics of Business Ecosystems Mean for the Strategy, Innovation, and Sustainability. Boston, MA: Harvard Business Press.

19. Moore JF (1997) The Death of Competition: Leadership and Strategy in the Age of Business Ecosystems. New York, NY: Harper Collins.

20. Desrochers P (2010) Industrial Ecology and the Rediscovery of Inter-Firm Recycling Linkages: Historical Evidence and Policy Implications. Industrial and Corporate Change 11: 1031-1057.

21. Frels JK, Shervani T, Srivastava RK (2003) The Integrated Networks Model: Explaining Resource Allocations in Network Markets. Journal of Marketing 67: 29-45.

22. Santos FM, Eisenhardt KM (2005) Organizational Boundaries and Theories of Organization. Organization Science, 16: 491-508.

23. Zacharakis AL, Shepherd DA, Coombs JE (2003) The Development of Venture-Capital-Backed Internet Companies: An Ecosystem Perspective. Journal of Business Venturing 18: 217-231.

Int J Comput Softw Eng

ISSN: 2456-4451 Volume 3. 2018. 145
IJCSE, an open access journal 
Citation: Lai CTA, Jackson PR, Jiang W (2018) Internet of Things Business Models in Ecosystem Context-Cases of Elevator Services. Int J Comput Softw Eng 3: 135. doi: https://doi.org/10.15344/2456-4451/2018/135

Page 12 of 12

24. Isckia T (2009) Amazon's Evolving Ecosystem: A Cyber-Bookstore and Application Service Provider. Canadian Journal of Administrative Sciences 26: 332-343

25. Lyer B, Davenport TH (2008) Reverse Engineering Google's Innovation Machines. Harvard Business Review.

26. Talvitie J (2011) Business Ecosystem Creation - Supporting Collaborative Business Concept Development. Tivit Business Forum.

27. Zott C, Amit R, Massa L (2011) The Business Model: Recent Developments and Future Research. Journal of Management, 37: 1019-1042.

28. Amit R, Zott C (2001) Value Creation in e-Business. Strategic Management Journal 22: 493-510.

29. Brandenburger AM, Stuart HW (1996) Value-Based Business Strategy. Journal of Economics and Management Strategy 5: 5-24.

30. Chesbrough HW (2010) Business Model Innovation: Opportunities and Barriers. Long Range Planning 43: 354-363.

31. Teece DJ (2010) Business Models, Business Strategy and Innovation Long Range Planning 43: 172-194.

32. Pavie X, Hsu E, Rödle HJT, Tapia RO (2013) How to Define and Analyse Business Model Innovation in Service. ESSEC Working.

33. Gassmann O, Frankenberger K, Csik M (2013) Geschäftsmodelle entwickeln: 55 innovative Konzepte mit dem St. Galler Business Mode Navigator. Munich: Hanser Verlag

34. Gassmann O, Frankenberger K, Csik M (2014) The Business Mode Navigator: 55 Models that will Revolutionise Your Business. Harlow: Pearson Education Ltd.

35. Gassmann O, Frankenberger K, Csik M (2014) Revolutionizing the Business Model. Management of the Fuzzy Front End of Innovation. Cham Springer.

36. Osterwalder A, Pigneur Y (2010) Business Model Generation: A Handbook for Visionaries, Game Changers, and Challengers. Hoboken, NJ: John Wiley \& Sons.

37. Kralewski D (2016) Business Models of Internet of Things. S. Wrycza, ed Information Systems: Development, Research, Applications, Education. SIGSAND/PLAIS. Lecture Notes in Business Information Processing Cham: Springer.

38. Visnjic I, Neely AD (2011) From Processes to Promise: How Complex Service Providers Use Business Model Innovation to Deliver Sustainable Growth. Cambridge: Cambridge Service Alliance, University of Cambridge.

39. Rong K, Hu GY, Lin Y, Shi Y J, Guo L, et al. (2015) Understanding Business Ecosystem Using a 6c Framework in Internet-of-Things Based Sectors. International Journal of Production Economics 159: 41-55.

40. Gassmann O, Zeschky M, Wolff T, Stahl M (2010) Crossing the IndustryLine: Breakthrough Innovating through Cross-Industry Alliances with "NonSuppliers". Long Range Planning 5: 639-654.

41. Rong K, Shi Y, Yu J (2013) Nurturing Business Ecosystem to Deal with Industry Uncertainties. Industrial Management \& Data Systems 133: 385402.

42. Sinfield JV, Calder E, McConnell B, Colson S (2012) How to Identify New Business Models. MIT Sloan Management Review 53: 84-90.

43. Weiller C, Neely A (2013) Business Model Design in an Ecosystem Context University of Cambridge Working Papers. Cambridge: Cambridge Service Alliance, University of Cambridge.

44. Carbone P (2009) The Emerging Promise of Business Ecosystems. Technology Innovation Management Resource.

45. Leminen S, Westerlund M, Rajahonka M, Siuruainen R (2012) Towards IOT Ecosystems and Business Models. Internet of Things, Smart Spaces, and Next Generation Networking. Lecture Notes in Computer Science. Springer, Berlin, Heidelberg.

46. Zott C, Amit R (2010) Designing Your Future Business Model: An Activity System Perspective. Long Range Planning 43: 216-226.

47. Leminen S, Rajahonka M, Westerlund M, Siuruainen R (2014) Ecosystem Business Models for the Internet of Things. European Association for Research on Service Conference, Helsinki, Finland. European Association for Research on Services (RESER)

48. Fleisch E, Weinberger M, Wortmann F (2015) Business Models and the Internet of Things (Extended Abstract). PodnarŽarko I, Pripužić $\mathrm{K}$ and Serrano M, eds, Interoperability and Open-Source Solutions for the Internet of Things. Lecture Notes in Computer Science. Cham: Springer.
49. Mazhelis O, Luoma E, Warma H (2012) Defining an Internet-of-Things Ecosystem. Andreev S, Balandin S and Koucheryavy Y, eds, Internet of Things, Smart Spaces, and Next Generation Networking. Lecture Notes in Computer Science. Berlin, Heidelberg: Springer.

50. Mejtoft $T$ (2011) Internet of Things and Co-Creation of Value. Xia F, Chan Z, Pan G, Yang L T and Ma J (eds) IEEE 4th International Conference on Internet of Things, Cyber, Physical and Social Computing. Institute of Electrical and Electronics Engineers.

51. Chan HC (2015) Internet of Things Business Models. Journal of Service Science and Management 8: 552.

52. Gambardella A, McGahan AM (2010) Business-Model Innovation: Genera Purpose Technologies and Their Implications for Industry Structure. Long Range Planning 43: 262-271.

53. Glova J, Sabol T, Vajda V (2014) Business Models for the Internet of Things Environment. Procedia Economics and Finance 15: 1122-1129.

54. Keskin T, Tanrisever F, Demirkan H (2016) Sustainable Business Models for the Internet of Things. ORMS Today, public article.

55. Bucherer E, Uckelmann D (2011) Business Models for the Internet of Things. Architecting the Internet of Things. Berlin: Springer.

56. Ju J, Kim, MS, Ahn JH (2016) Prototyping Business Models for loT Service. Procedia Computer Science 91: 882-890.

57. Westerlund M, Leminen S, Rajahonka M (2014) Designing Business Models for the Internet of Things. Technology Innovation Management Review.

58. Vargo SL, Lusch RF (2004) Evolving to a New Dominant Logic for Marketing. Journal of Marketing 68: 1-17.

59. Nuseibah A, Wolff C (2015) Business Ecosystem Analysis Framework International Conference on Intelligent Data Acquisition and Advanced Computing Systems: Technology and Applications (IDAACS), Warsaw, Poland 2: 501-505.

60. Fleisch E (2010) What is the Internet of Things? An economic perspective Economics, management and financial markets 2: 125-157.

61. Turber S, vom Brocke J, Gassmann O, Fleisch E (2014) Designing Business Models in the Era of Internet of Things. Advancing the Impact of Design Science: Moving from Theory to Practice, DESRIST, Lecture Notes in Computer Science 8463: 17-31.

This article was originally published in a special issue:

\section{Internet of Things}

Handled by Editor:

\section{Dr. Makhoul Abdallah}

Department of Computer Science

University of Franche-comté

France 